\title{
A Seasonal and Multilevel Association Based Approach for Market Basket Analysis in Retail Supermarket
}

\author{
S. Rana and M. N. I. Mondal
}

\section{ABSTRACT}

\begin{abstract}
Market Basket Analysis is an observational data mining methodology to investigate the consumer buying behavior patterns in retail Supermarket. It analyzes customer baskets and explores the relationship among products that helps retailers to design store layouts, make various strategic plans and other merchandising decisions that have a big impact on retail marketing and sales. Frequent itemsets mining is the first step for market basket analysis. The association rules mining uncovers the relationship among products by looking what products the customers frequently purchase together. In retail marketing, the transactional database consists of many itemsets that are frequent only in a particular season however not taken into consideration as frequent in general. In some cases, association rules mining at lower data level with uniform support doesn't reflect any significant pattern however there is valuable information hiding behind it. To overcome those problems, we propose a methodology for mining seasonally frequent patterns and association rules with multilevel data environments. Our main contribution is to discover the hidden seasonal itemsets and extract the seasonal associations among products in additionally with the traditional strong regular rules in transactional database that shows the superiority for making season based merchandising decisions. The dataset has been generated from the transaction slips in large supermarket of Bangladesh that discover 442 more seasonal patterns as well as 1032 seasonal association rules in additionally with the regular rules for $0.1 \%$ minimum support and $50 \%$ minimum confidence.
\end{abstract}

Keywords: Association Rules, frequent pattern, seasonal rules, multilevel associations.

\section{INTRODUCTION}

Market basket analysis is a set of analytical techniques aimed to discover the associations and correlations among products by analyzing the customer's shopping baskets [1]. In retail marketing, it is used to investigate what another related product is more likely to buy, whenever a customer purchases a product. For example, when a customer purchase Noodles, in most of cases, buys Eggs as well. Mining such association rules among products in retail market plays important roles to create new business strategies, design offer and discounts coupons, store layout design and other merchandising decisions that improve the benefits of the organizations as well as customers satisfactions.

The retail market is highly seasonal. For a season-based marketing, the item Hot-Coffee has highly demand in winter however the Cold Drinks is not sells in winter seasons in general. Evaluating the changes in customer demand with the change of seasons are the more challenging task against the market basket analysis.

The uniform support threshold based traditional
Published Online: October 20, 2021

ISSN: $2736-5492$

DOI : 10.24018/ejcompute.2021.1.4.31

S. Rana*

Department of Computer Science \& Engineering, Rajshahi University of Engineering \& Technology, Bangladesh. (e-mail: sohelranacse052@gmail.com) M. N. I. Mondal

Department of Computer Science \& Engineering, Rajshahi University of Engineering \& Technology, Bangladesh. (e-mail: nimbd109@gmail.com)

*Corresponding Author association rules mining with fixed data level sometimes fail to show all significant patterns hiding behind it. Many lower supported itemsets are missed for higher support threshold value and the number of patterns explodes for the lower support threshold level. Multilevel reduced support-based association mining will provide the extreme advantage to a retailer to improve the effectiveness of sales and marketing in retail Supermarket.

The frequent pattern and association rules mining methodology first proposed by Agrawal et al. [1]. The support and confidence are two measures commonly used to derive the association rules [2]. The support measure calculates the frequency of itemsets in transactional database (i.e., how many times it appears in customer transactions) and the itemsets which satisfy the user specified minimum support threshold level is considered as frequent itemsets. The confidence is a degree of the accuracy and credibility of each discovered pattern to derive the strong association rules.

The Apriori [1], FP-Growth [3], Eclat [5] and K-Apriori [6] are the most widely used data mining algorithms for frequent itemstes mining as well as association rules 
generation. The Apriori algorithm is the popular and first developed algorithm for frequent pattern mining, but the main limitation is, it requires multiple scanning of transaction datasets and generates huge number of candidate itemsets that reduce the efficiency of algorithm [8]. Eclat algorithm uses the vertical data format and applies the depth-first search technique that is faster than Aprori and requires less memory for small datasets [5]. It requires more time and space when the number of transactions is relatively large. The FP-Growth is a tree based, currently most popular, faster and memory efficient algorithm for frequent pattern mining in large transactional database [9]. Depending on the demands and applications, several aspects of market basket analysis have been proposed such as the periodic-frequent patterns mining [12], fuzzy association rules mining [13], positive and negative association mining [17], generalized association rules, spatial rules [18], quantitative rules, interesting association rules, inter-transaction rules, temporal association rules [23] etc.

In this paper, a season based frequent pattern and association rules mining approach with multilevel datasets have been proposed. The tree based Fp-growth concepts are used to generate the frequent itemsets from transactional database. The generated multilevel seasonal association rules help to discovering more specific and applicable hidden knowledge which plays an important role in inventory management for a retailer. Seasonal pattern and associations mining will be milestones to a retailer for designing seasonal offer \& discount coupons, seasonal plan and layout design and any others season-based business decisions

\section{Frequent PATtern Mining}

A frequent pattern is a set of items(s) that occurs frequently in transactional database. A measure called support is used to check the frequency of an itemset. Suppose TDB is a transactional database where each transaction $\mathrm{T}$ is associated with unique Tid number and the set of items $I=\left\{i_{1}, i_{2}, \ldots, i_{n}\right\}$ purchased by the customers. The support of an itemset $\mathrm{X}$ is the ratio of containing $\left|\mathrm{T}^{\mathrm{X}}\right|$ in $|\mathrm{T}|$ where, $|\mathrm{T}|$ is the total number of transactions in TDB. An itemset is defined as a frequent pattern if the support count is greater than or equal to the user specified minimum support threshold $(\sigma)$. A pattern with $\beta$ number of items is called a $\beta$-pattern.

$\operatorname{Sup}(X)=\frac{\left|\mathrm{T}^{\mathrm{X}}\right|}{|\mathrm{T}|}=\frac{\# \text { of transactions containing item } \mathrm{X}}{\text { Total number of transactions in TDB }}$

$$
\text { Frequent }(\mathrm{D}, \sigma)=\{\mathrm{X} \subseteq \mathrm{I} \mid \operatorname{Sup} \geq \sigma\}
$$

TABLE I: THE SAMPLE TRANSACTIONAL DATASET (TDB)

\begin{tabular}{cc}
\hline \hline Transaction Id (Tid) & Set of Items \\
\hline \hline 1 & $\mathrm{a}, \mathrm{i}, \mathrm{p}, \mathrm{f}, \mathrm{d}, \mathrm{c}, \mathrm{h}$ \\
2 & $\mathrm{~g}, \mathrm{~b}, \mathrm{l}, \mathrm{a}, \mathrm{h}, \mathrm{m}, \mathrm{c}, \mathrm{p}$ \\
3 & $\mathrm{k}, \mathrm{e}, \mathrm{l}, \mathrm{a}, \mathrm{m}$ \\
4 & $\mathrm{f}, \mathrm{h}, \mathrm{m}, \mathrm{k}$ \\
5 & $\mathrm{a}, \mathrm{c}, \mathrm{f}, \mathrm{h}, \mathrm{j}, \mathrm{g}, \mathrm{p}$ \\
\hline \hline
\end{tabular}

The tree-based FP-growth approach follows the three consecutive steps to mining the frequent itemsets from transactional database.
Step 1:

- Scan the complete database and count the support value for each item.

- Discard all the non-frequent items (support value doesn't satisfies the minimum threshold value).

- Generate the frequent item list (F_list) by sorting the items in descending order of their support.

Step 2:

- Scan the transactions one by one and maps it on a tree.

- Construct the complete tree structure (Fp_tree)

Step 3: for the generated frequent item list (F_list).

- For each item in F_list, construct the conditional pattern-base and its conditional $\mathrm{Fp}$ _tree.

- Repeat for each newly generated conditional tree until the resulting tree is empty or at single path.

- Discover the frequent patterns by taking all combinations of the sub-path.

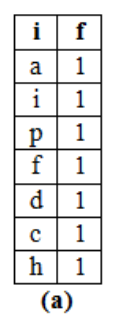

(a)

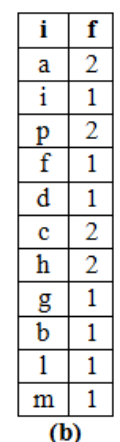

(b)

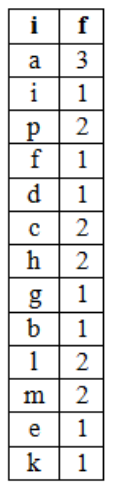

(c)

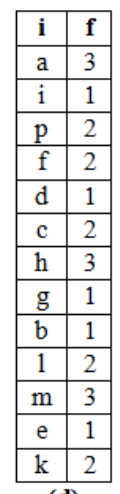

(d)

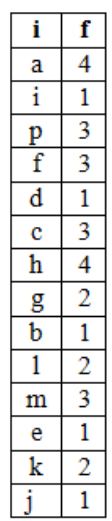

(e)

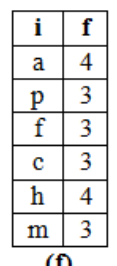

(f)

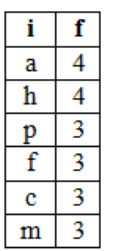

(g)
Fig. 1. Frequent item list (F_list) generation. After scanning the (a) 1st, (b) 2nd, (c) 3rd, (d) 4th and (e) final transaction. (f) Frequent item list after discarding the non-frequent items and $(\mathrm{g})$ final sorted frequent (F_list).

The Table I represents a transactional database with 5 transactions of 12 unique items. The frequent items list (F_List) with user specified minimum support threshold (Min_sup) $60 \%$ (i. e. $3 / 5$ ) is generated at Fig. 1 . The first transaction consists of the item $a, i, p, f, d, c$ and $h$. Therefore, after scanning the first transaction, the support count is 1 for those items. The items $g, b, l, a, h, m, c$ and $p$ are appearing at second transaction from which the support count of $a, p, c$ and $h$ is 2 because of they are second time occurring in database. Similarly, after scanning all the transactions the total support count for all items is shown in Fig. 2 (e). After removing the non-frequent items (who doesn't satisfy the threshold level $60 \%$ ) from the list, the final sorted frequent item list (F_list) is reflected at Fig. 2 (g).

TABLE II: UPDATED DATASET WITH FREQUENT ITEMS ONLY

\begin{tabular}{ccc}
\hline \hline Transaction Id (Tid) & Set of Items & Sorted Frequent Items \\
\hline \hline 1 & $\mathrm{a}, \mathrm{i}, \mathrm{p}, \mathrm{f}, \mathrm{d}, \mathrm{c}, \mathrm{h}$ & $\mathrm{a}, \mathrm{h}, \mathrm{p}, \mathrm{f}, \mathrm{c}$ \\
2 & $\mathrm{~g}, \mathrm{~b}, \mathrm{l}, \mathrm{a}, \mathrm{h}, \mathrm{m}, \mathrm{c}, \mathrm{p}$ & $\mathrm{a}, \mathrm{h}, \mathrm{p}, \mathrm{c}, \mathrm{m}$ \\
3 & $\mathrm{k}, \mathrm{e}, \mathrm{l}, \mathrm{a}, \mathrm{m}$ & $\mathrm{a}, \mathrm{m}$ \\
4 & $\mathrm{f}, \mathrm{h}, \mathrm{m}, \mathrm{k}$ & $\mathrm{h}, \mathrm{f}, \mathrm{m}$ \\
5 & $\mathrm{a}, \mathrm{c}, \mathrm{f}, \mathrm{h}, \mathrm{j}, \mathrm{g}, \mathrm{p}$ & $\mathrm{a}, \mathrm{h}, \mathrm{p}, \mathrm{f}, \mathrm{c}$ \\
\hline \hline
\end{tabular}

By considering only the items in F_list, the updated dataset of Table I is shown in Table II. At the next step, the Fp_tree has been generated by scanning each transaction of updated 
frequent items dataset. The tree structures for each transaction are shown into Fig. 2 respectively. Only the frequent items will take part in the construction of Fp_tree. After scanning the final transaction, the complete scenario of frequent items with their paths is reflected at Fig. 2(e).

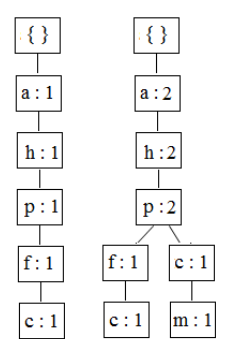

(a)

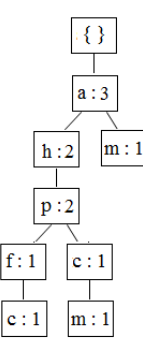

(c)

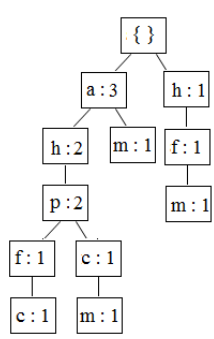

(d)

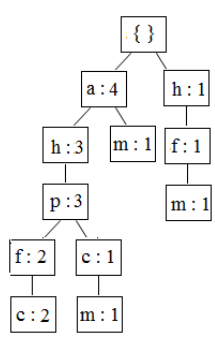

(e)
Fig. 2. Fp_tree generation. After scanning the (a) $1^{\text {st }}$, (b) $2^{\text {nd }}$, (c) $3^{\text {rd }}$, (d) $4^{\text {th }}$ and (e) final transaction.

Finally, the conditional pattern base for all the frequent items is being generated from the final Fp-tree. The conditional pattern base of the item $\mathrm{f}$ is $[\{\mathrm{a}, \mathrm{h}, \mathrm{p}\}: 2,\{\mathrm{~h}\}: 1]$ means the item $f$ are appears 2 times with the frequent itemset $\{\mathrm{a}, \mathrm{p}, \mathrm{h}\}$ and one time with the item $\mathrm{h}$ only. All the conditional patterns reflected on the Fp-tree are represented at the Table III. To mining the frequent patterns recursively, the algorithm generates the conditional Fp-tree for all the conditional pattern base and repeat the process until the resulting tree is empty or containing only single path. All the combinations of items in a single path are considered as a frequent pattern. There is total 18 patterns have been generated from the above dataset with $60 \%$ minimum support threshold (Table IV).

TABLE III: CONDITIONAL PATTERN BASE FOR EACH FREQUENT ITEM

\begin{tabular}{cc} 
TABLE III: CONDITIONAL PATTERN BASE FOR EACH FREQUENT ITEM \\
\hline \hline Frequent Items & Conditional Pattern Base \\
\hline \hline $\mathrm{a}$ & - \\
$\mathrm{h}$ & $\mathrm{a}: 3$ \\
$\mathrm{p}$ & $\mathrm{ah}: 3$ \\
$\mathrm{f}$ & $\mathrm{ahp}: 2, \mathrm{~h}: 1$ \\
$\mathrm{c}$ & $\mathrm{ahpf}: 2, \mathrm{ahp}: 1$ \\
$\mathrm{~m}$ & $\mathrm{ahpc}: 1, \mathrm{a}: 1, \mathrm{hf}: 1$ \\
\hline \hline
\end{tabular}

TABLE IV: FREQUENT PATTERNS WITH 60\% SUPPORT THRESHOLD.

\begin{tabular}{cc}
\hline \hline Items in a Pattern & Frequent Patterns \\
\hline \hline 1-pattern & $\{\mathrm{a}\},\{\mathrm{h}\},\{\mathrm{p}\},\{\mathrm{f}\},\{\mathrm{c}\},\{\mathrm{m}\}$ \\
2-pattern & $\{\mathrm{a}, \mathrm{h}\},\{\mathrm{a}, \mathrm{p}\},\{\mathrm{h}, \mathrm{p}\},\{\mathrm{h}, \mathrm{f}\},\{\mathrm{h}, \mathrm{c}\},\{\mathrm{p}, \mathrm{c}\},\{\mathrm{a}, \mathrm{c}\}$ \\
3-pattern & $\{\mathrm{a}, \mathrm{h}, \mathrm{p}\},\{\mathrm{a}, \mathrm{h}, \mathrm{c}\},\{\mathrm{a}, \mathrm{p}, \mathrm{c}\},\{\mathrm{h}, \mathrm{p}, \mathrm{c}\}$ \\
4-pattern & $\{\mathrm{a}, \mathrm{h}, \mathrm{p}, \mathrm{c}\}$ \\
\hline \hline
\end{tabular}

\section{Seasonally Frequent Pattern Mining}

Customer demand changes with the season. By analyzing season-based customer demands, designing various seasonal offers and discount coupons, changing store layouts, and creating various seasonal business plans provide the extreme advantages to a retailer to increase the sales and improve the customer satisfactions. Seasonally frequent pattern mining approach finds different seasonal patterns hidden in the database that are not usually caught in traditional pattern manning system. In the case of seasonal pattern mining, the database is clustered on the basis of different seasons and the pattern mining algorithms are simultaneously run in each seasonal cluster along with the overall dataset. As a result, after scanning the entire database, a separate Sf_list is generated for each season along with the frequent $\mathrm{F}_{-}$list. In the same way, for each Sf_list, the Sfp_tree has been generated to mine seasonal patterns in additionally with overall frequent patterns which are used to find the seasonbased associations next.

TABLE V: A SAMPLE TRANSACTIONAL DATABASE WITH 3 SEASONS

\begin{tabular}{cccccc}
\hline \hline $\mathrm{T}_{\mathrm{id}}$ & Items & $\mathrm{T}_{\text {id }}$ & Items & $\mathrm{T}_{\text {id }}$ & Items \\
\hline \hline 1 & $\mathrm{a}, \mathrm{d}$ & 6 & $\mathrm{a}, \mathrm{c}, \mathrm{e}$ & 11 & $\mathrm{a}, \mathrm{f}$ \\
2 & $\mathrm{a}, \mathrm{b}, \mathrm{c}$ & 7 & $\mathrm{~b}, \mathrm{e}$ & 12 & $\mathrm{c}, \mathrm{d}$ \\
3 & $\mathrm{~b}, \mathrm{c}$ & 8 & $\mathrm{a}, \mathrm{c}, \mathrm{e}$ & 13 & $\mathrm{a}, \mathrm{e}$ \\
4 & $\mathrm{a}, \mathrm{b}$ & 9 & $\mathrm{a}, \mathrm{d}$ & 14 & $\mathrm{c}, \mathrm{f}$ \\
5 & $\mathrm{~b}, \mathrm{c}$ & 10 & $\mathrm{c}, \mathrm{e}$ & 15 & $\mathrm{a}, \mathrm{c}, \mathrm{f}$ \\
\hline \hline
\end{tabular}

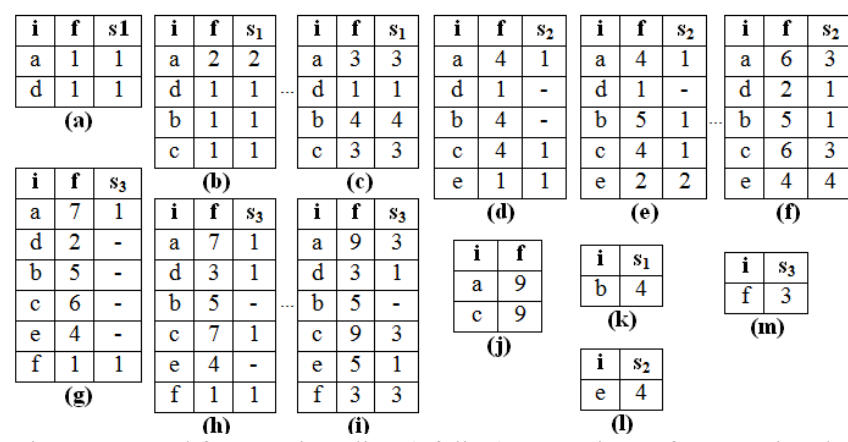

Fig. 3. Seasonal frequent item lists (Sf lists) generation. After scanning the (a) $1 \mathrm{st}$, (b) $2 \mathrm{nd}$, (c) $5 \mathrm{th}$, (d) $6 \mathrm{th}$, (e) $7 \mathrm{th}$, (f) 10th, (g) 11th, (h) 12th, and (i) final transaction. (j) Final frequent items list (F_list), (k) Final $\mathrm{S}_{1} \mathrm{f}$ _list, (l) Final $\mathrm{S}_{2} f$ list and $(\mathrm{m})$ Final $\overline{\mathrm{S}}_{3} \mathrm{f}$ _list.

Suppose the transactional database of Table $\mathrm{V}$ has been partitioned into three seasons. The first season $\left(\mathrm{s}_{1}\right)$ contains the first five transections, next five transections are appearing at second season $\left(\mathrm{s}_{2}\right)$ and the season three $\left(\mathrm{s}_{3}\right)$ consists the last five transections. The scanning process to generate the seasonal Sf_lists in additionally with original $\mathrm{F}_{\text {_list }}$ is shown in Fig. 3. After scanning the $5^{\text {th }}, 10^{\text {th }}$ and final $15^{\text {th }}$ transactions, we can get the final seasonal support count for each season respectively. The $6^{\text {th }}$ scan is the beginning transaction for second season; therefore, the seasonal support count is 1 for the first appearing items in season two. After scanning all the transactions, we can summarize that, for the $60 \%$ support threshold ( 9 for F_list and 3 for Sf_lists) the items $\mathrm{a}$ and $\mathrm{c}$ is a frequent item, item $\mathrm{b}$ is a frequent item only in season 1, item e and $f$ are the frequent items in the season 2 and season 3 respectively.

\section{Association Rules Mining}

Association rule is an if-then scenario represented as a form of $\mathrm{X} \rightarrow \mathrm{Y}$, where $\mathrm{X}$ and $\mathrm{Y}$ are two disjoint sets. It discovers the dependency of items on other items and finds the interesting associations among products in transactional database. The highly dependable items (strong association rules) those are purchase together can be put together within a shelf in order to increase the sales. Two measures support and confidence are used to measure the strength of the associations (i.e., effectiveness of the rules). The support calculates the frequency of a rule that is how many times it appears in customer transactions in transactional database. The confidence measures how often item in $\mathrm{Y}$ appear in customer transactions that contain the item $X$. It is the 
conditional probability that a transaction having $\mathrm{X}$ also contains $\mathrm{Y}$.

$$
\begin{aligned}
& \operatorname{Sup}(\mathrm{X} \rightarrow \mathrm{Y})=\frac{\left|\mathrm{T}^{\mathrm{X} \cup \mathrm{Y}}\right|}{|\mathrm{T}|}=\frac{\# \text { of Ts containing }\{\mathrm{X}, \mathrm{Y}\}}{\text { Total number of Ts in TDB }} \\
& \operatorname{Conf}(\mathrm{X} \rightarrow \mathrm{Y})=\frac{\left|\mathrm{T}^{\mathrm{X}} \mathrm{Y}\right|}{\left|\mathrm{T}^{\mathrm{X}}\right|}=\frac{\# \text { of Ts containing }\{\mathrm{X}, \mathrm{Y}\}}{\# \text { of Ts containing }\{\mathrm{X}\}}
\end{aligned}
$$

The strong association rules allow only the rules with support $\geq$ min_sup and confidence $\geq$ min_conf, where min_sup and min_conf are the corresponding minimum thresholds values for support and confidence defined by the user. The two-step approach is used to mining the association rules. Firstly, mining all the frequent itemsets from transactional database and secondly, generate the association rules for mined frequent itemsets so that it can prune all the non-frequent itemsets without computing the confidence values. The association rules for all the generated patterns (Table IV) with $80 \%$ minimum confidence (min_conf) level are computed at Table VI. There are 32 rules has been generated for that dataset. In the same way seasonal rules are generated from the seasonal Sf_lists. By Applying the knowledge gained from such rules for making product-based merchandising decisions can easily lead to increase sales and profits.

TABLE VI: STRONG ASSOCIATION RULES FOR FREQUENT PATTERNS OF TABLE IV WITH $80 \%$ CONFIDENCE THRESHOLD

\begin{tabular}{llll}
\hline \hline \multicolumn{4}{c}{ Association Rules } \\
\hline \hline$\{\mathrm{h}\} \rightarrow\{\mathrm{a}\}$ & $\{\mathrm{h}, \mathrm{p}\} \rightarrow\{\mathrm{a}\}$ & $\{\mathrm{p}, \mathrm{c}\} \rightarrow\{\mathrm{a}\}$ & $\{\mathrm{c}\} \rightarrow\{\mathrm{h}, \mathrm{p}\}$ \\
$\{\mathrm{p}\} \rightarrow\{\mathrm{a}\}$ & $\{\mathrm{a}, \mathrm{p}\} \rightarrow\{\mathrm{h}\}$ & $\{\mathrm{p}\} \rightarrow\{\mathrm{a}, \mathrm{c}\}$ & $\{\mathrm{h}, \mathrm{p}\} \rightarrow\{\mathrm{c}\}$ \\
$\{\mathrm{p}\} \rightarrow\{\mathrm{h}\}$ & $\{\mathrm{p}\} \rightarrow\{\mathrm{a}, \mathrm{h}\}$ & $\{\mathrm{a}, \mathrm{c}\} \rightarrow\{\mathrm{p}\}$ & $\{\mathrm{c}\} \rightarrow\{\mathrm{a}, \mathrm{h}, \mathrm{p}\}$ \\
$\{\mathrm{f}\} \rightarrow\{\mathrm{h}\}$ & $\{\mathrm{a}, \mathrm{h}\} \rightarrow\{\mathrm{p}\}$ & $\{\mathrm{c}\} \rightarrow\{\mathrm{a}, \mathrm{p}\}$ & $\{\mathrm{a}, \mathrm{h}, \mathrm{p}\} \rightarrow\{\mathrm{c}\}$ \\
$\{\mathrm{c} \rightarrow\{\mathrm{h}\}$ & $\{\mathrm{h}, \mathrm{c}\} \rightarrow\{\mathrm{a}\}$ & $\{\mathrm{a}, \mathrm{p}\} \rightarrow\{\mathrm{c}\}$ & $\{\mathrm{c}\} \rightarrow\{\mathrm{a}, \mathrm{h}, \mathrm{c}\}$ \\
$\{\mathrm{c}\} \rightarrow\{\mathrm{p}\}$ & $\{\mathrm{a}, \mathrm{c}\} \rightarrow\{\mathrm{h}\}$ & $\{\mathrm{p}, \mathrm{c}\} \rightarrow\{\mathrm{h}\}$ & $\{\mathrm{a}, \mathrm{h}, \mathrm{c}\} \rightarrow\{\mathrm{p}\}$ \\
$\{\mathrm{p}\} \rightarrow \mathrm{c}\}$ & $\{\mathrm{c}\} \rightarrow\{\mathrm{a}, \mathrm{h}\}$ & $\{\mathrm{p}\} \rightarrow\{\mathrm{h}, \mathrm{c}\}$ & $\{\mathrm{a}, \mathrm{p}, \mathrm{c}\} \rightarrow\{\mathrm{h}\}$ \\
$\{\mathrm{c}\} \rightarrow\{\mathrm{a}\}$ & $\{\mathrm{a}, \mathrm{h}\} \rightarrow\{\mathrm{c}\}$ & $\{\mathrm{h}, \mathrm{c}\} \rightarrow\{\mathrm{p}\}$ & $\{\mathrm{h}, \mathrm{p}, \mathrm{c}\} \rightarrow\{\mathrm{a}\}$ \\
\hline \hline
\end{tabular}

\section{Multilevel Association Mining}

In retail market, the items are often forming a hierarchical structure. At the lower-level dataset, same product with different brands, flavors or packet sizes are considered as different individual items. As a result, numbers of single items in transactional database are increased and many lower supported items are missed while the minimum support threshold level is higher. Oppositely the number of patterns explodes when the support threshold level is lower. To solve this problem the proposed approach converted the dataset into three different levels. The first level dataset, each individual item is associated with brand name, flavor name and their packet size if available. The dataset at the next level does not consider the packet size and flavors name of a product although the brand names are still under consideration. At the last level, an item with different size, flavors, and brands is considered as a single item in transactional dataset.

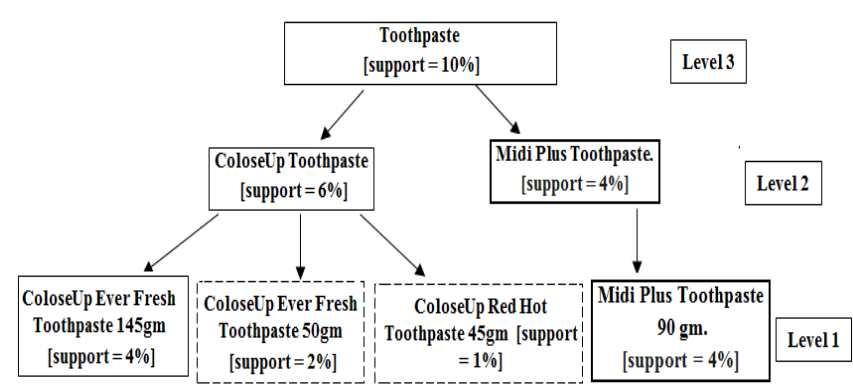

Fig. 4. Example of a multilevel datasets of items.

The items ColoseUp Ever Fresh Toothpaste 145gm, ColoseUp Ever Fresh Toothpaste 50gm, ColoseUp Red Hot Toothpaste 45gm and Midi Plus Toothpaste 90gm are different individual products with support $4 \%, 2 \%, 1 \%$ and $4 \%$ respectively at Level 1 of Fig. 4 . The Level 2 ignores the packet size and flavors so the 5 distinct items in Level 1 are now converted into two items only with support $6 \%$ and $4 \%$ respectively. Level 3 combined those two different brands of Toothpaste into single item, resulting in the support of Toothpaste is now $10 \%$ in overall dataset. The items at the lower level are expected to have comparatively lower support therefore setting the fixable support threshold by analyzing the level of the dataset will discover more valuable and applicable hidden patterns in retail transactional database.

\section{RESULTS AND DISCUSSION}

\section{A. Data Collections}

The real-world transactional data are used for this study. The dataset (SupershopBD1) has been generated from the one-year transaction slips in large super shop of Bangladesh. Different preprocessing techniques are applied, and the final dataset contains three features: transaction number, transaction date and list of items for a customer transaction. The preprocessed dataset contains 99760 transactions for 2382 unique items (Table VII). The dataset is converted into 3 different levels. The seasonal patterns are generated by considering summer, winter, and spring seasons based on the transaction date of customer transactions in database. The Table 1 shows the details about the dataset. The experimental environment is a Windows 10 computer with $8 \mathrm{~GB}$ of RAM and 64 bit Core i5 a 6 th generation processor. All the programs are written in Java.

TABLE VII: THE DATASET

\begin{tabular}{cccc}
\hline \hline Dataset & $\begin{array}{c}\text { No. of } \\
\text { transactions }\end{array}$ & Levels & $\begin{array}{c}\text { No. of } \\
\text { unique items }\end{array}$ \\
\hline \hline $\begin{array}{c}\text { SupershopBD1 } \\
\text { (Generated from the }\end{array}$ & Level 1 & 2382 \\
transaction slips in large & 99760 & Level 2 & 1663 \\
Super shop of Bangladesh) & & Level 3 & 453 \\
\hline \hline
\end{tabular}

\section{B. Results}

The total number of frequent patterns as well as association rules including the seasonal aspects with different minimum support thresholds (Min_sup) values is shown in Table 8. When the minimum support threshold is raised, many patterns are left out because they are not able to satisfy the threshold level. Association rules have been generated with the minimum confidence $50 \%$. The algorithm generates all 
the frequent patterns of the entire dataset as well as it extracts the hidden seasonal patterns for each specific season. Then it generates the rules by finding co-relations among frequent itemsets with at least $50 \%$ confidence and discovers the seasonal association rules for seasonal products. There are 642 additional seasonal frequent patterns has been generated with the 636 overall frequent patterns for the user define support threshold $0.1 \%$. Those 636 frequent patterns and 642 seasonal patterns generate the 1193 strong regular association rules and 1032 seasonal association rules respectively. The number of patterns and rules with different cases are shown in Table VIII and Table IX respectively.

TABLE VIII: NUMBER OF DISCOVERED PATTERNS WITH DIFFERENT

\begin{tabular}{ccccc}
\multicolumn{5}{c}{ MIN_SUP } \\
\hline \hline \multirow{2}{*}{ Min_Sup(\%) } & $\begin{array}{c}\text { Frequent } \\
\text { Patterns }\end{array}$ & \multicolumn{2}{c}{ Seasonal Frequent Patterns } \\
\hline \hline 0.1 & 636 & Summer & Winter & Spring \\
\hline 0.2 & 434 & 147 & 203 & 92 \\
0.3 & 401 & 83 & 167 & 81 \\
0.4 & 376 & 72 & 89 & 68 \\
0.5 & 213 & 58 & 67 & 39 \\
\hline \hline
\end{tabular}

Our study shows that relatively more seasonal products are sold out at winter season in our country. As a result, the seasonal frequency pattern and association rules are higher in the winter season than spring and summer (Fig. 5a and 5b).

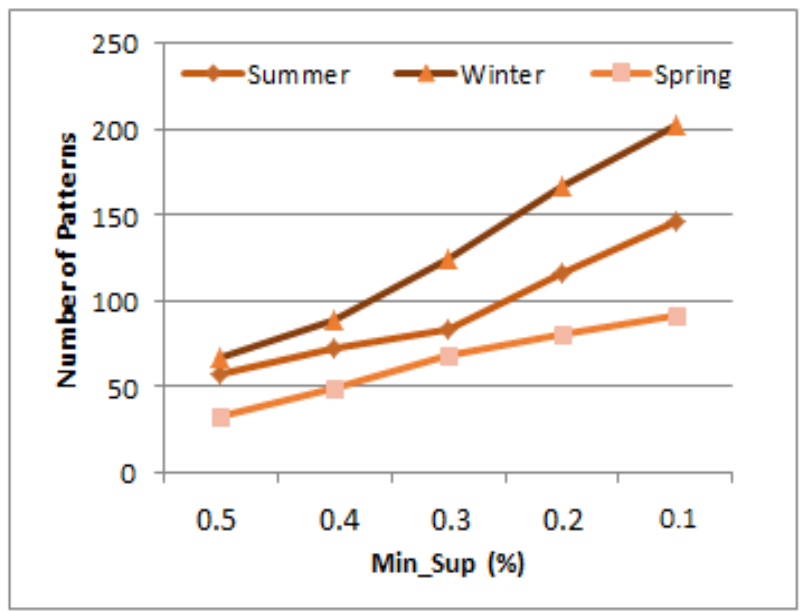

(a)

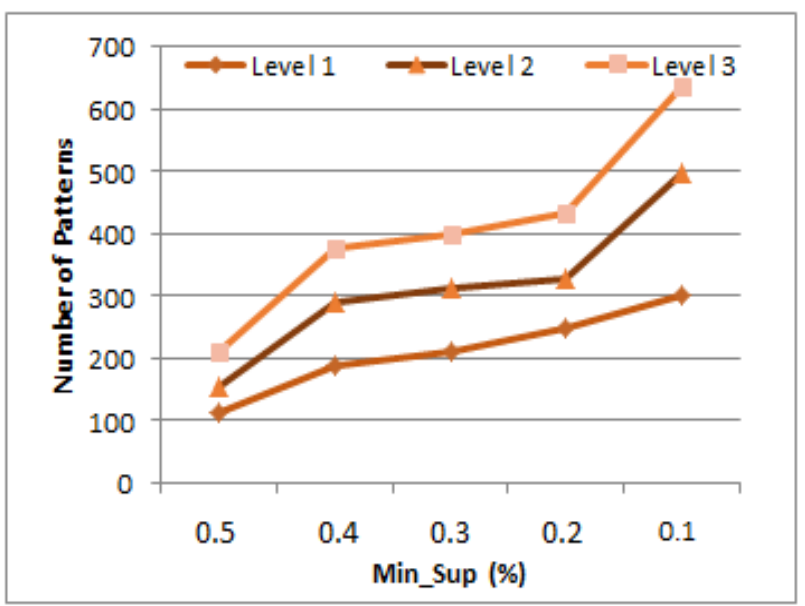

(c)
For the $0.3 \%$ minimum support, there are 125 frequent patterns and 300 associations with $50 \%$ confidence are generated in winter season and oppositely 197 associations with 83 frequent patterns and 112 associations with 68 frequent patterns are being generated in summer and spring season, respectively.

TABLE IX: NUMBER OF DISCOVERED ASSOCIATION RULES WITH DIFFERENT MIN_SUP

\begin{tabular}{ccccc}
\hline \multicolumn{5}{c}{ DIFFERENT MIN_SUP } \\
\cline { 3 - 5 } Min_Sup(\%) & $\begin{array}{c}\text { Association } \\
\text { Rules }\end{array}$ & \multicolumn{2}{c}{ Seasonal Association Rules } \\
\cline { 3 - 5 } & 1193 & Summer & Winter & Spring \\
\hline \hline 0.1 & 787 & 262 & 522 & 199 \\
0.2 & 703 & 197 & 300 & 173 \\
0.3 & 622 & 128 & 222 & 82 \\
0.4 & 594 & 94 & 109 & 53 \\
0.5 & & &
\end{tabular}

Although the support threshold value depends on the location, size, type, and other parameters of a store, it has to be set by considering the data levels in a multilevel dataset. Lower level datasets require lower support otherwise many quality patterns are missed, oppositely whenever we set lower support for higher level datasets, it will generates much more additional non actionable patterns. For the same support threshold values, the curve of increasing the number of patterns with increasing the data level is shown in Fig. 5.

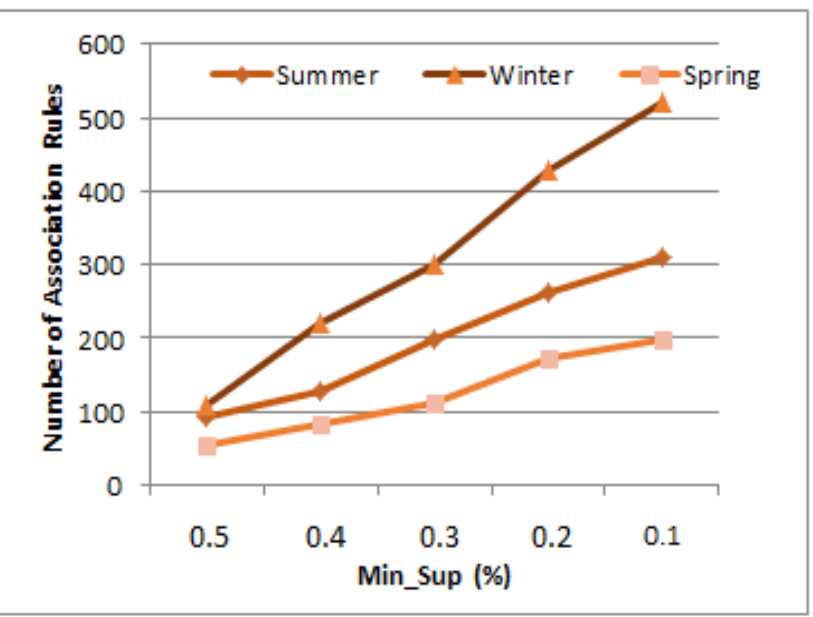

(b)

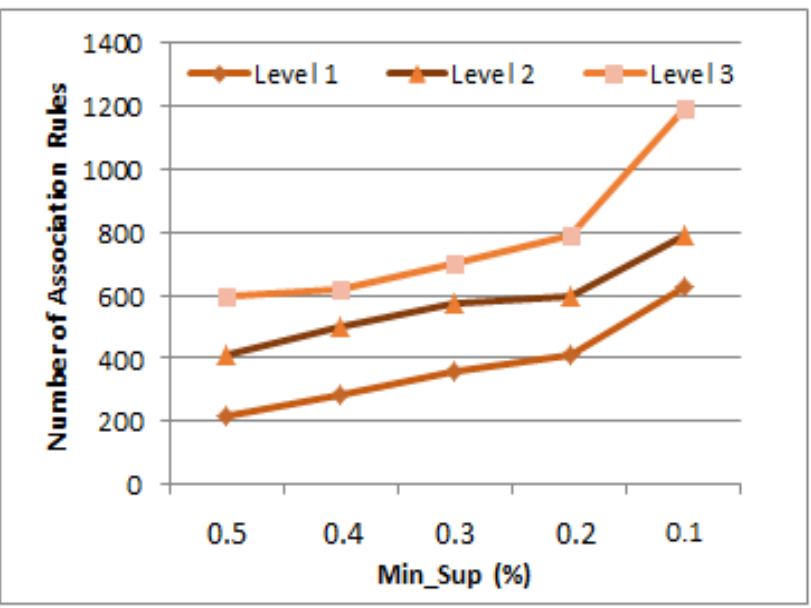

(d)

Fig. 5. Patterns and association rules for different Min_sup with different seasons and data levels. (a) Patterns for different seasons with different Min_sup (b) rules with different seasons (c) patterns for different data levels and (d) rules for different data levels. 


\section{CONCLUSIONS}

In this paper we have proposed an approach for mining seasonal association rules along with the overall strong regular rules in multilevel data environments. Although most of the generated rules are somewhat predictable for a retailer, it is extremely difficult to tracking season-based product affinities and leveraging on them for a large super shop where retailer deals with the huge number of products daily. However, it is important for the retailer to know exactly what items are purchased together and in what season. Such information provides the better understanding of consumers' demands that can be used as a basis for decisions making for different merchandizing activity including seasonal promotional support, inventory control, layout design, cross and up-sale campaigns etc. The discovered patterns and rules may not be unusual, but they are useful and actionable in retail Supermarket. As a part of future work, we are investigating the alternative search technique to reduce the execution time and required search space for large datasets.

\section{ACKNOWLEDGMENT}

The author would like to thank all the super shops that have provided their transactional data for this research. The author extends thanks to Rajshahi University of Engineering \& Technology and Pundra University of Science \& Technology for providing the laboratory support for this research.

\section{REFERENCES}

[1] R. Agrawal, T. Imieliński, and A. Swami, "Mining association rules between sets of items in large databases," Proceedings of the ACM SIGMOD international conference on Management of data, pp. 207216, 1993.

[2] A. R. Pillai, D. A. Jolhe, "Market Basket Analysis: Case Study of a Supermarket," Advances in Mechanical Engineering, Singapore: Springer, 2021, pp. 727-734.

[3] A. H. Nasyuha, J. Jama, R. Abdullah, Y. Syahra, Z. Azhar, J. Hutagalung, and B. S. Hasugian, "Frequent pattern growth algorithm for maximizing display items," Telkomnika, vol. 19, no. 2, pp. 390-396, 2021.

[4] F. Kurniawan, B. Umayah, J. Hammad, S. M. S. Nugroho, and M. Hariadi, "Market Basket Analysis to identify customer behaviors by way of transaction data," Knowledge Engineering and Data Science, vol. 1 , no. 1 , pp. $20-25,2018$.

[5] Z. Ma, J. Yang, T. Zhang and F. Liu, "An improved eclat algorithm for mining association rules based on increased search strategy," International Journal of Database Theory and Application, vol. 9, no. 5, pp. 251-66, 2016.

[6] L. C. M. Annie and A. D. Kumar, "Market basket analysis for a supermarket based on frequent itemset mining," International Journal of Computer Science Issues, vol. 9, no. 5, pp. 257-64, 2012.

[7] Y. L. Chen, K. Tang, R. J. Shen, Y. H. Hu, "Market basket analysis in a multiple store environment," Decision support systems, vol. 40, no. 2, pp. 339-354, 2005.

[8] M. A. Khan, K. M. Solaiman, and T. H. Pritom, "Market basket Analysis for improving the effectiveness of marketing and sales using Apriori, FP Growth and Eclat Algorithm," PhD dissertation, BRAC Univ., Bangladesh, 2017.

[9] A. Ilham, A. D GS, F. E. Laumal, N. Kurniasih, A. Iskandar, G. Manulangga, I. B. A. I. Iswara and R. Rahim, "Market Basket Analysis Using Apriori and FP-Growth for Analysis Consumer Expenditure Patterns at Berkah Mart in Pekanbaru Riau," Journal of Physics: Conference Series, vol. 1114, no. 1, pp. 012131, 2018.

[10] M. Hossain, A. S. Sattar and M. K. Paul, "Market Basket Analysis Using Apriori and FP Growth Algorithm," $22^{\text {nd }}$ International Conference on Computer and Information Technology, IEEE, pp. 1-6, 2019.
[11] S. Nasreen, M. A. Azam, K. Shehzad, U. Naeem and M. A. Ghazanfar, "Frequent pattern mining algorithms for finding associated frequent patterns for data streams: A survey," Procedia Computer Science, vol. 37, pp. 109-16, 2014.

[12] R. U. Kiran, M. Kitsuregawa and P. K. Reddy, "Efficient discovery of periodic-frequent patterns in very large databases, " Journal of Systems \& Software, vol. 112, pp. 110-121, 2016.

[13] H. Zheng, J. He, G. Huang, Y. Zhang, and H. Wang, "Dynamic optimisation based fuzzy association rule mining method," International Journal of Machine Learning and Cybernetics, vol. 10, no. 8, pp.2187-2198, 2019.

[14] A. A. Raorane, R. V. Kulkarni and B. D. Jitkar, "Association ruleextracting knowledge using market basket analysis," Research Journal of Recent Sciences, vol. 1, pp. 19-27, 2012.

[15] M. Kaur S. Kang, "Market Basket Analysis: Identify the changing trends of market data using association rule mining," Procedia Computer Science, vol. 85, pp. 78-85, 2016.

[16] Y. A. Ünvan. "Market basket analysis with association rules," Communications in Statistics-Theory and Methods. Vol. 50, no. 7, pp. 1615-1628, 2021.

[17] X. Wu, C. Zhang, and S. Zhang, "Efficient mining of both positive and negative association rules," ACM Trans. Information Systems, vol. 22, no. 3, pp. 381-405, 2004

[18] W. Shi, A. Zhang and G. I. Webb, "Mining significant crisp-fuzzy spatial association rules," International Journal of Geographical Information Science, vol. 32, no. 6, pp. 1247-1270, 2018.

[19] M. A. Valle and G. A. Ruz, "Finding hierarchical structures of disordered systems: An application for market basket analysis," IEEE Access, vol. 9, pp. 1626-1641, 2020.

[20] Y. Liu and Y. Guan, "Fp-growth algorithm for application in research of market basket analysis," IEEE International Conference on Computational Cybernetics, IEEE, pp. 269-272, 2008.

[21] J. Han, H. Cheng, D. Xin, and X. Yan, "Frequent pattern mining: current status and future directions," Data mining and knowledge discovery, vol. 15, no. 1, pp. 55-86, 2007.

[22] S. Rana, M. N. I. Mondal, "A Generic Approach for Relative RegularFrequent Pattern Mining in Retail Supermarket," Middle East Journal of Applied Science \& Technology, vol. 4, no. 2, pp. 34-42, 2021.

[23] S. A. Aljawarneh, V. Radhakrishna and A. Cheruvu, "VRKSHA: a novel tree structure for time-profiled temporal association mining," Neural Computing and Applications, vol. 32, no. 21, pp. 16337-16365, 2020.

[24] V. M. Nofong, "Discovering productive periodic frequent patterns in transactional databases," Annals of Data Science, vol. 3, no. 3, pp. 235249,2016

[25] A. Griva, C. Bardaki, K. Pramatari and D. Papakiriakopoulos, "Retail business analytics: Customer visit segmentation using market basket data," Expert Systems with Applications, vol. 100, pp. 1-16, 2018.

[26] S. Rana, "Analysis of regular-frequent patterns in large transactional databases," International Journal of Computer Sciences and Engineering, vol. 6, no. 7, pp. 1-5, 2018.

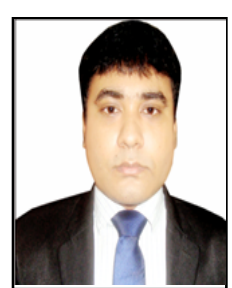

S. Rana is currently pursuing his M. Sc. Engineering degree in CSE from the Department of Computer Science and Engineering, Rajshahi University of Engineering Technology (RUET), Bangladesh. He obtained his B. Sc. Engineering degree in CSE from the Department of Computer Science and Engineering, Bangabandhu Sheikh Mujibur Rahman Science and Technology University, Gopalganj, Bangladesh in 2016. He is currently working as Lecturer in Department of Computer Science and Engineering, Pundra University of Science and Technology, Bogura, Bangladesh. His research focuses on data mining, pattern recognition and machines learning. $\mathrm{He}$ has over five years of teaching and research experience.

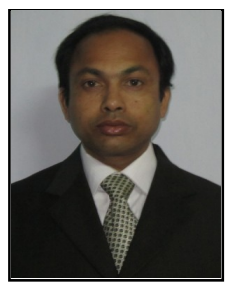

M. N. I. Mondal received BE Degree in EEE from the Department of Electrical \& Electronic Engineering, RUET Bangladesh in 2000 (Exam. of 1997, Session 1993 - 94), ME degree in Information \& Communication Technologies (ICT) from the School of Engineering and Technology, Asian Institute of Technology, Thailand in 2008 and $\mathrm{PhD}$ degree in Information Engineering from the Department of Information Engineering, Hiroshima University, Japan in 2012. He joined as a lecturer to the Department of Computer Science \& Engineering, RUET in 2001. In 2004 and 2013, he 
became Assistant Professor and Associate Professor in the same Department respectively. From March 2012 to September 2012 and from May 2013 to April 2014, respectively he was Visiting Research Scholar and Specially Appointed visiting Lecturer in the Department of Information Engineering, Hiroshima University, Japan. He joined as a Professor in June 2015 in the same Department. He has been serving as a CISCO instructor since 2006. He has published his contributions extensively in journals, conference proceedings. He served as an Organizing Chair, a PC member, reviewer and sub-reviewer for many Journals and Conferences such as Journal of Foundation of Computer Science, Journal of Communication and Computer, International Journal of Networking and Computing, IEICE, APDCM, PDP, ICNC, CANDAR, IJPEDS, ICPP and so on. He is an IEEE member (93455891) and a Fellow (F/10973) of Institution of Engineers, Bangladesh. He has organized many reputed International and National conferences, workshops, and Programming Contests. 